\title{
UMA ANÁLISE VARIACIONISTA DA COLOCAÇÃO DOS PRONOMES CLÍTICOS NO PORTUGUÊS FALADO EM LUANDA-ANGOLAI
}

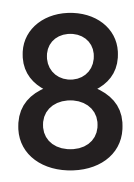

\author{
A VARIATION ANALYSIS OF THE PLACE- \\ MENT OF CLITIC PRONOUNS IN PORTU- \\ GUESE SPOKEN IN LUANDA-ANGOLA
}

\begin{abstract}
ARAÚJO, Silvana Silva de Farias
Doutora em Língua e Cultura pela Universidade Federal da Bahia (UFBA), professora titular da Universidade Estadual de Feria de Santana (UEFS)

\section{SILVA, Manoel Crispiniano Alves}

Graduando em Letras Vernáculas da Universidade Estadual de Feira de Santana (UEFS)
\end{abstract}

\section{RESUMO}

Com base na Sociolinguística Variacionista (LABOV, 2008 [1972]), e na perspectiva do contato, este estudo apresenta a ordem da colocação dos pronomes clíticos em lexias verbais simples na norma culta e popular do português falado em Luanda, capital de Angola. Para isso, utilizamos o corpus formado por 24 entrevistas sociolinguísticas do projeto "Em busca das raízes do português brasileiro", sediado na Universidade Estadual de Feira de Santana. A fim de testar a correlação das variáveis independentes com a variável dependente, utilizamos, para esse fim, o programa computacional GoldvarbX (SANKOFF; TAGLIAMONTE; SMITH, 2005). Assim, os dados de Luanda, devidamente levantados e analisados, serviram de base para investigar as aproximações e os distanciamentos dessa variedade com o português brasileiro (PB). Desse modo, esta pesquisa buscou contribuir com o debate sobre a relevância do contato entre línguas na formação sócio-histórica do PB, no sentido que busca investigar um fenômeno variável na língua portuguesa falada em uma ex-colônia de Portugal. Os resultados obtidos mostram que a colocação pré-verbal apresentou uma maior frequência, perfazendo uma frequência de $75 \%$ de um total de 507 ocorrências, não havendo registros de mesóclise no corpus. Nesse sentido, no que tange ao fenômeno em foco, nota-se 
uma aproximação entre o PB e o português angolano (PA). O programa Goldvarb $X$ selecionou como favorecedora da implementação da próclise as variáveis linguísticas "tipo de oração", "clítico" e "elemento que antecede o verbo". E, em relação às variáveis extralinguísticas, foram selecionadas como estatisticamente relevantes "escolaridade" e "local de nascimento".

Palavras-chave: clíticos; português angolano; português brasileiro.

\section{ABSTRACT}

Based on Variationist Sociolinguistics (LABOV, 2008 [1972]), and in the perspective of contact, this research presents the order of placement of clitic pronouns in simple verbal lexias in the cultured and popular norm of Portuguese spoken in Luanda, capital of Angola. For that, we used a corpus formed by 24 sociolinguistic interviews of the project "Em busca das raízes do português brasileiro", based in the State University of Feira de Santana. In order to test the correlation of the independent variables with the dependent variable, we used the Goldvarb X computational program (SANKOFF; TAGLIAMONTE; SMITH, 2005). Thus, Luanda data, duly analyzed, served as a basis to highlight the approaches and distances of this variety with Brazilian Portuguese (BP). Thus, this research sought to contribute to the debate on the relevance of the contact between languages in the sociohistorical formation of $\mathrm{PB}$, in the sense that it seeks to investigate a variable phenomenon in the Portuguese language spoken in a former colony of Portugal. The results show that the pre-verbal placement had a higher frequency, with a percentage $75 \%$ of a total of 507 occurrences, and there were no records of mesoclisis in this corpus. In this sense, regarding the phenomenon in focus, an approximation between BP (Brazilian portuguese) and Angolan Portuguese (AP). The Goldvarb X program selected thelinguistic variables "type of sentence", "clitic" and "element that precedes the verb" as favoring the implementation of the proclisis. And, in relation to the extra linguistic variables, "schooling" and "place of birth" were selected.

Keywords: Clitics; Portuguese Angolan; Brazilian Portuguese. 


\section{CONSIDERAÇÕES INICIAIS}

A sócio-história do Brasil foi marcada por sucessivos contatos linguísticos, inicialmente entre os portugueses e os falantes das línguas autóctones de diversas etnias, e, de forma mais expressiva, com os negros escravizados que adquiriram o português como segunda língua de uma forma assistemática, por meio de oitiva. (MATTOS E SILVA, 2004)

Em situações de contato entre línguas pode formar-se uma nova língua, como é o caso dos pidgins e das línguas crioulas, ou apenas uma nova variedade de uma das línguas da situação em contato, mas com alterações em sua gramática, como ressalta Áraujo (2017, p. 51), com base em Lucchesi (2001) "[...] o intenso contato entre línguas diversas e ininteligíveis na sócio-história do português brasileiro não chegou a acarretar a formação de um crioulo prototípico, e sim um processo de transmissão linguística irregular".

Embora tenha havido o intenso contato entre línguas na sóciohistória do PB, comcontextos favoráveis à formação de uma língua pidgin ou crioula, encontra-se desacredita a hipótese de que a variedade brasileira é o resultado de uma crioulização, mas "isso não significa que o contato entre línguas não esteja na base da notável diferenciação da língua portuguesa no Brasil frente a sua congênere de Portugal"(LUCCHESI, 2012, p. 45).

Desse modo, para uma compreensão da realidade linguística brasileira, é importante a realização de estudos comparativos entre o PB e o "português de Camões", mas também é necessária a realização de estudos contrastivos entre o PB e a língua portuguesa falada em países africanos, a exemplo de Angola, bem como em comunidades brasileiras marcadas etnicamente, para que assim, possamos buscar elementos que possibilitem aferir as consequências do contato linguístico na constituição da heterogeneidade linguística do Brasil.

Para a pesquisa aqui delineada, foi escolhido o tema que a gramática tradicional (GT) chama de pronomes átonos, embora esse termo seja inadequado do ponto de vista linguístico.Cagliari (1992, p. 54 apud SCHEI 2003, p. 23), sobre essa questão, afirma que o vocábulo "átono" é impróprio ao se tratar dos pronomes no PB, afinal "a posição de próclise permite que o pronome receba um acento tônico (o que torna ridículo chamar esses pronomes de 'átonos' de antemão)". Por isso, no presente trabalho, chamaremos de colocação dos pronomes clíticos. 
A literatura tem mostrado que a língua portuguesa do Brasil é caracterizada pela anteposição do pronome clítico (CARNEIRO, 2003; FERREIRA, ALKMIM, 2003; LOBO, 1992). Sabemos que o PA e o PB são variedades históricas formadas por meio de sucessivos contatos linguísticos, e, assim, aventamos a hipótese de que a colocação com maior frequência no PA seja a próclise, havendo, dessa forma, uma aproximação com o PB. Assim, temos como objetivo analisar como se realiza esse fenômeno no português falado em Luanda, capital de Angola, investigando os contextos sintáticos e os fatores sociais que atuam nesse uso linguístico variável. Além disso, objetivamos desenvolver um estudo comparativo entre pesquisas já realizadas que analisaram esse fenômeno na realidade sociolinguística brasileira, averiguando as semelhanças ou diferenças entre ambas as variedades de matriz portuguesa, nos que diz respeito aos contextos aqui investigados.

Este artigo está estruturado da seguinte forma, além desta seção introdutória, na seção dois, procuramos sistematizar estudos já realizados sobre o objeto de estudo em discussão, na terceira, destacamos a teoria e os procedimentos metodológicos e logo em seguida, na seção 04, a socialização dos resultados alcançados e findamos com as referências utilizadas neste trabalho.

\section{REVISÃO DE LITERATURA: A COLOCAÇÃO DOS CLÍTICOS NO PB E NO PE}

Desde o século XIII (período em que começa a escrita em línguas românicas) predominava a ênclise no $P E$, semelhantemente ao que ocorre nos dias, como afirma Schei (2003, p.42): "Se compararmos o sistema de colocação do século XIII descrito por Ramsden com o sistema atual do PE vemos que são muito parecidos [...]".

A partir do século $\mathrm{XVI}^{1}$, no $\mathrm{PE}$, houve uma forte tendência à próclise, como observam Galves e Lobo (2009, p.176):

Os séculos XVI e XVII são fortemente proclíticos, mas, a partir do século XVIII, assiste-se a um retorno da ênclise, que se torna majoritária entre os autores nascidos na segunda metade do século (cf. GALVES; BRITO; PAIXÃO DE SOUSA, 2006; doravante, GPBS, 2006), e passa a ser a única possibilidade no português europeu moderno.

1. Para uma análise sobre a colocação dos clíticos no século XVI, ver. Lobo (1992) 
Carneiro (2016), ao estudar a colocação dos clíticos no português falado na cidade de Feira de Santana-BA, propõe-se a investigar se há variação na fala dos informantes feirenses no que concerne a esse fenômeno. Para esse fim, a pesquisadora utiliza a amostra de fala do projeto "A língua portuguesa no semiárido baiano-Fase III". Analisa as duas vertentes formadoras do PB- a norma culta e a popularinvestigando somente os contextos sintáticos com verbos na forma finita e chega a seguinte conclusão "[...] em todos os contextos sintáticos, sem exceção, na fala oral culta e não culta, a colocação dos clíticos ocorre em posição de próclise" (CARNEIRO, 2016, 146). Portanto, podemos concluir que, em relação a esse fenômeno sintático na realidade linguística brasileira predomina a generalização da variante proclítica, havendo uma aproximação entre a norma culta e a popular do português feirense.

Ferreira e Alckmin (2011) estudaram a colocação dos clíticos no dialeto mineiro, realizando um estudo contrastivo entre a prescrição gramatical e o uso. Para isso, utilizaram corpora formados por entrevistas sociolinguísticas de falantes nascidos nos municípios mineiros de Mariana,Ouro Preto e Belo Horizonte e notaram que há uma grande diferença entre o uso efetivo da língua e a prescrição gramatical: "Das estruturas utilizadas pelos falantes contendo clíticos, 75\% não estavam de acordo com a GT"(FERREIRA; ALKMIM, 2011, p.03). Desse modo,os resultados alcançados convergem com o estudo de Carneiro (2016), no sentido de confirmar que, no Brasil, há uma ampla preferência pela posição pré-verbal:

Concluímos, a partir da análise dos dados aqui utilizados, que a diferença entre a prescrição da regra e o uso é mais significativa quando a gramática tradicional prescreve o uso da ênclise, o que atesta a preferência do PB pela próclise (FERREIRA; ALKMIN 2011, p.04).

Desse modo, percebemos que o PB é marcado por uma tendência à próclise sem restrição de contexto sintático, fato que pode ser entendido, por uma explicação diacrônica:

O português do século XVI foi, por assim dizer, o ponto de partida do $\mathrm{PB}$, dado que é neste século que começa a colonização, mas o PB não só manteve a preferência pela próclise nos contextos que tinham próclise no Século XVI; a próclise predominante chegou até a abranger a posição inicial (SCHEI, 2013, p. 47). 
Portanto, a colocação dos clíticos é um dos fenômenos sintáticos que distancia as duas variedades da língua portuguesa (o PB do PE). Como bem colocam Galves e Lobo (2009), no século XVI e XVII, o PE é caracterizado como um período de incremento da próclise, sendo o século XVI o início da colonização portuguesa no Brasil, fato que explica o porquê de o PB dar preferência à próclise sem restrição de contexto. As pesquisas de Carneiro (2016) e Ferreirae Alkmin (2011) são, pois, representativas sobre a colocação mais frequente no PB falado.

\section{QUADRO TEÓRICO-METODOLÓGICO}

Adota-se o arcabouço teórico-metodológico da Sociolinguística Variacionista (LABOV, (2008[1972]), também rotulada de Sociolinguística Quantitativa, por operar com números e tratamento estatístico dos dados coletados, ou ainda, denominada de Teoria da Variação e da Mudança Linguística, já que, a partir da consideração de variáveis explanatórias, pode se constatar se a variação caminha, ou não, para uma mudança. Essa é a linha adotada em função de ser considerada teoricamente coerente e metodologicamente eficaz para a descrição da língua em uso numa perspectiva variacionista.

Os dados utilizados nesta pesquisa foram levantados a partir do corpus do banco de dados pertencentes ao projeto "Em busca das raízes do português brasileiro", sediado no Núcleo de Estudos da Língua Portuguesa (NELP) da Universidade Estadual de Feira de Santana (UEFS), constituído por entrevistas sociolinguísticas do tipo DID (Diálogo entre Informante e Documentador) que foram gravadas entre o ano de 2008 e 2013 na provínciade Luanda. A amostra encontra-se estratificada da seguinte forma: Sexo (masculino, feminino), Faixa etária (I- 20 a 30 anos/II- 36 a 50 anos/ III- acima de 52 anos), Escolaridade (baixa ou nula/ superior), Língua Materna (Português/ línguas africanas) e Local de Nascimento (Capital/ Interior).

Controlaram-se as variáveis extralinguísticas anteriormente citadas e as variáveis linguísticas: tipo de oração, clítico, elemento que antecede o verbo e oração coordenada sindética. Para obtenção dos pesos relativos e valores percentuais, utilizou-se o programa computacional Goldvarb X.

Para descrever a ordem de colocação dos pronomes clíticos, consideram-se apenas ocorrências em lexias verbais simples, ou seja, estrutura oracional formada com apenas um verbo, a exemplo de usos como (i) "Me chamo A. V. M." (Faixa III, M, NC), com verbo na forma 
finita, não fazendo parte desta pesquisa os clíticos que se figuram em orações na forma infinita e em complexos verbais, como se observa, por exemplo, em (ii) "me arrependo porque agora já sou mulher sei me virar, sei viver a vida aqui em Luanda normalmente, estamos indo" (A.E, Faixa I, F, NP).

\section{OS CLÍTICOS NO PORTUGUÊS FALADO EM LUANDA: UMA ANÁLISE VARIACIONISTA}

$\mathrm{Na}$ literatura linguística, muitas pesquisas têm procurado descrever a ordem de colocação dos clíticos na variedade brasileira em sua sincrônica e diacrônica seja no PB falado (FERREIRA, ALKMIN, 2011; LOBO, 1992; VIEIRA, 2003, entre outros), seja no PB escrito (SCHEI, 2003; SANTOS, 2007-09; GALVES, LOBO, 2009; ANDRADE, CARNEIRO, 2014; VIEIRA, 2003). Este trabalho procura não realizar um estudo contrastivo entre o PB face ao PE sobre o fenômeno variável em análise, mas lançar um novo olhar, fazendo uma descrição das variáveis linguísticas e extralinguísticas responsáveis pelo condicionamento da ordem dos clíticos no português falado em Luanda na sua norma culta e não culta.

\subsection{A variável dependente}

Antes de apresentar a descrição das variáveis linguísticas e extralinguísticas, reitera-se que a base de dados desta pesquisa perfaz um total de 507 ocorrências encontradas na variedade angolana. Os resultados alcançados estão expostos na Tabela 01:

Tabela 1: Distribuição da colocação dos clíticos em lexias verbais simples no português falado em Luanda

\begin{tabular}{c|c|c}
\hline Posição do clítico & Número de ocorrências/Total & Percentual \\
\hline Pré-verbal & $380 / 507$ & $75 \%$ \\
\hline Pós-verbal & $127 / 507$ & $25 \%$ \\
\hline
\end{tabular}

Os resultados acima descritos mostram que a colocação mais recorrente na fala luandense é a pré-verbal, com o índice de $75 \%$ (380 ocorrências), não havendo registro no corpus de mesóclise, apresentando, portanto, uma semelhança com os resultados alcançados por Vieira (2003, p.05) ao estudar a variedade brasileira, moçambicana 
e europeia: "A colocação intraverbal está em flagrante desuso na modalidade oral da Língua Portuguesa".De acordo com Lobo (1992, p.131),"Mesmo em sua norma culta, o português do Brasil apresenta uma preferência pela anteposição do clítico". Assim, notamos que há uma aproximação entre a variedade brasileira e a angolana e, um distanciamento dessas face à europeia e a moçambicana (VIEIRA, 2003). Com base nos dados encontrados no corpus aqui examinado e em estudos já realizados sob o fenômeno variável em debate, é possível concluir que a próclise é a posição que prevalece na realidade sociolinguística destas duas ex-colônias portuguesas, a brasileira e a angolana.

\subsection{As variáveis selecionadas}

Nesta seção, procura-se sistematizar as variáveis independentes selecionadas como favorecedoras à aplicação da variante proclítica em estruturas formadas por um único verbo. As variáveis eleitas pelo Goldvarb X, em ordem de relevância estatística foram as seguintes: "Escolaridade", "Elemento que antecede o verbo", "Naturalidade do falante", "Tipo de oração" e "Clítico".Foram descartadas as variáveis "Faixa etária", "Sexo", "Oração coordenada sindética" e "Língua materna".

\subsubsection{As variáveis linguísticas}

Encontra-se, na tabela a seguir, a descrição do comportamento da variável tipo de clítico:

Tabela 2: Atuação do fator tipo de clítico na aplicação da próclise em estrutura com lexias verbais simples no Português de Luanda

\begin{tabular}{c|c|c|c}
\hline Tipo de Clítico & Apl./ Ocorrências & Porcentagem & Pesos Relativos \\
\hline $\mathrm{Me}$ & $206 / 252$ & $81 \%$ & $\mathbf{. 5 3}$ \\
\hline $\mathrm{Nos}$ & $34 / 43$ & $79 \%$ & $\mathbf{. 5 7}$ \\
\hline $\mathrm{Te}$ & $20 / 21$ & $95 \%$ & $\mathbf{. 7 3}$ \\
\hline $\mathrm{Se}$ & $79 / 136$ & $58 \%$ & .35 \\
\hline $\mathrm{Lhe}$ & $37 / 44$ & $84 \%$ & $\mathbf{. 6 4}$ \\
\hline $\mathrm{A}(\mathrm{s}) / \mathrm{O}(\mathrm{s})$ & $3 / 10$ & $30 \%$ & .17 \\
\hline
\end{tabular}


Como pode ser observado na tabela acima, não foi encontrada nenhuma ocorrência da forma "vos" na variedade angolana. Os resultados encontrados assemelham-se aos de Lobo (1992, p.172), em que a pesquisadora, ao estudar o PB culto contemporâneo, concluiu que o clítico "vos" pode ser considerado um arcaísmo linguístico, sendo que essa forma não faz parte do comportamento linguístico dos brasileiros: "[...] podendo-se afirmar, de resto, ser essa uma forma totalmente extinta do português brasileiro contemporâneo, em qualquer das suas variantes diatópicas, diafásicas ou diastráticas".

Nota-se que os clíticos exercem interferência em sua própria colocação na estrutura oracional, havendo uma forte tendência à próclise. Os pronomes de primeira e segunda pessoa do singular (me, te) e do plural (nos) e o de terceira (Ihe) apresentam um padrão de comportamento majoritariamente proclítico.

Desse modo, o clítico acusativo de terceira pessoa o(s), a(s) desfavorece a aplicação da próclise, obtendo peso relativo de (.17). Pelo baixo número de ocorrências no corpus, não podemos afirmar que esse pronome está desaparecendo da fala vernácula do português falado em Luanda. Contudo, os resultados aqui obtidos convergem com os alcançados por Peterson (2010, p.112) na modalidade escrita do português brasileiro. Segundo o pesquisador, "os clíticos o (s)/a(s) apresentaram .03 de peso relativo na aplicação da próclise, constituindo elemento fortemente desfavorecedor dessa variante".

Nesse sentido, esses resultados apontam para uma tendência a substituição do clítico acusativo nas variedades da língua portuguesa (BRITO, 2004; CYRINO, 1993; NUNES, 1993, entre outros). Assim, o mesmo se verifica com o clítico "se", pois esse também foge ao padrão de colocação identificado pelos demais clíticos, obtendo peso relativo de .35, no favorecimento da implementação da próclise, apresentando, pois, uma semelhança com o PB (PETERSON, 2010).

A variável "tipo de oração" foi selecionada como estatisticamente favorecedora da anteposição do clítico. Antes de apresentar os resultados, destaca-se que dentre os contextos controlados, "Oração intercalada" e "Oração exclamativa", nesses contextos o uso da próclise foi categórico. Os resultados encontrados para esse grupo de fator são apresentados na tabela seguinte: 
Tabela 3: Uso da próclise segundo a variável tipo de oração em estrutura com um único verbo no Português de Luanda

\begin{tabular}{c|c|c|c}
\hline Tipo de Oração & Apl./ Ocorrências & Porcentagem & Pesos Relativos \\
\hline $\begin{array}{c}\text { Verbo em Posi- } \\
\text { ção Inicial (V1) }\end{array}$ & $22 / 31$ & $71 \%$ & .59 \\
\hline $\begin{array}{c}\text { Sujeito sem fa- } \\
\text { tor de próclise }\end{array}$ & $79 / 110$ & $71 \%$ & .39 \\
\hline $\begin{array}{c}\text { Oração Coorde- } \\
\text { nada Sindética }\end{array}$ & $72 / 104$ & $69 \%$ & .26 \\
\hline $\begin{array}{c}\text { Oração Subor- } \\
\text { dinada Desen- } \\
\text { volvida }\end{array}$ & $123 / 136$ & $90 \%$ & .74 \\
\hline Depois de pausa & $54 / 94$ & $57 \%$ & .48 \\
\hline $\begin{array}{c}\text { Oração Princi- } \\
\text { pal }\end{array}$ & $11 / 13$ & $84 \%$ & .47 \\
\hline
\end{tabular}

Há uma convergência entre os compêndios gramaticais em prescreverem que não pode iniciar período ou oração com pronome oblíquo átono (ROCHA LIMA, 2001; BECHARA, 2009), contudo, "[n] o PB contemporâneo, prevalece a próclise em orações com verbo em posição inicial (V1), um contexto exclusivamente enclítico (V-cl) ao longo da história da língua portuguesa em Portugal" (CARNEIRO, 2016, p. 141). Assim, fica evidente que se trata de uma inovação do $\mathrm{PB}$, pois até os falantes não escolarizados de Portugal preferem categoricamente a ênclise no referido contexto (VIEIRA, 2012).

Verifica-se que, assim como no português do Brasil, a variedade angolana, nesse contexto sintático, é estatisticamente favorecedora da variante proclítica (.59) Os exemplos a seguir, extraídos do corpus examinado, servem para ilustrar o que foi supracitado:

(1)

INF: "Com a família, ah... é... isso tem acontecido principalmente visitar os irmãos, sobrinhos, os primos, enfim...já... isso acontece. Nos encontramos, às vezes, entre amigos, hoje agora já não tenho, as amizades aqui, todos eles têm outros rumos, né?" [...] (A., Faixa II, H, $\mathrm{NC})^{2}$

2. Legenda: Faixa Etária: Faixa I (20 a 30 anos), Faixa II (36 a 50 anos), Faixa III (acima de 52 anos), Sexo: M (Masculino), F (Feminino), NC (Falante da Norma Culta), NP (Falante da Norma Popular). 
(2)

INF: "[...] depois 2010 caiu mais de novo, todo ano até 2011 assim que tentou se recuperar um bocado e tava na faculdade de Direito..."

DOC: Sim... pública ou privada?

INF:"..pública. E tinha que desistir, desistiu mesmo. E sofreu mais a parte da cabeça. Me prejudicou muito, ainda está assim" (L., Faixa II, M,NC)

DOC: Podia me dizer seu nome completo?

INF: Me chamo A. V. M. (Faixa III, M, NC)

(4)

DOC:E onde é que a tia conheceu o seu marido? $\mathrm{F}, \mathrm{NP})$

INF:"Se conhecemos mesmo aqui em Luanda" (P.A.B, Faixa II,

De acordo com Rocha Lima (2011), o uso da próclise é obrigatório nas orações subordinadas. Em consonância com o que é prescrito pela tradição gramatical, na língua portuguesa do Brasil, esse contexto é essencialmente proclítico, seja na modalidade oral (LOBO,1992), seja na escrita (SHEl,2003). O mesmo se atesta no PA, sendo esse contexto fortemente favorecedor da variante proclítica (.74). Dessa forma, há uma confluência sociolinguística entre ambas as variedades da língua portuguesa. Apresentam-se alguns exemplos das orações subordinadas (substantiva, adverbial e relativa) encontradas no corpus:

DOC: Como é o comportamento dos taxistas? O que é que acha?

INF: Os taxistas se comportam muito mal, quando chove, porque querem encurtar as distâncias, aumentar o preçário, isso é que nos complica tanto (L., Faixa I, F, NC).

DOC: Entendi, então você veio sozinha?

INF: Eu vim sozinha, depois de eu fazer os, os quinze, dezesseis anos, é... quando eu me encontrei com primo do meu pai, na rua na praça do São Paulo e pronto (J., Faixa II, F, NP) 
(3)

"[...] eu apanhei uma fraqueza que me parece que o mundo pra mim acabô, que o mundo pra mim acabô porque eu fiquei sem nada, fiquei sem dinheiro não tinha nada para mim comer na minha casa, não tinha, não tinha nada para passar as festa [...]" (A.E, Faixa I, F, NP)

Os pesos relativos das variantes "Sujeito sem fator de próclise (.39) e "Oração coordenada sindética" (.26), verifica-se que esses contextos são desfavorecedores do uso da próclise. Por outro lado, "Depois de pausa" (.48) e em "Oração principal" (.47) consideram-se como contextos neutros.

Na sequência, encontram-se os resultados da variável "Elemento que antecedente o verbo"

Tabela 04: Favorecimento da variante proclítica segundo a variável elemento que antecede imediatamente o verbo:

\begin{tabular}{c|c|c|c}
\hline $\begin{array}{c}\text { Elemento antece- } \\
\text { dente ao verbo }\end{array}$ & $\begin{array}{c}\text { Valor de aplica- } \\
\text { ção/ ocorrências }\end{array}$ & Porcentagem & $\begin{array}{c}\text { Pesos Relati- } \\
\text { vos }\end{array}$ \\
\hline Nenhum elemento & $67 / 117$ & $57 \%$ & .16 \\
\hline $\begin{array}{c}\text { SN- Sujeito No- } \\
\text { minal }\end{array}$ & $36 / 61$ & $59 \%$ & .34 \\
\hline $\begin{array}{c}\text { SN- Sujeito Pro- } \\
\text { nome Pessoal }\end{array}$ & $64 / 71$ & $90 \%$ &. $\mathbf{6 0}$ \\
\hline $\begin{array}{c}\text { SN -SujeitoInde- } \\
\text { finido }\end{array}$ & $9 / 10$ & $90 \%$ & .69 \\
\hline $\begin{array}{c}\text { SN- Sujeito de- } \\
\text { monstrativo }\end{array}$ & $1 / 2$ & $50 \%$ & .16 \\
\hline $\begin{array}{c}\text { Sintagma adver- } \\
\text { bial de negação }\end{array}$ & $59 / 60$ & $98 \%$ & .96 \\
\hline $\begin{array}{c}\text { Outros sintagmas } \\
\text { adverbiais }\end{array}$ & $42 / 52$ & $80 \%$ & .52 \\
\hline Vocativo & $1 / 2$ & $50 \%$ & .07 \\
\hline
\end{tabular}


Considerando-se o elemento que precede o verbo, pode-se afirmar que, quando a lexia verbal vem precedida na estrutura frasal por "Sintagma Nominal (SN) pronome pessoal", "SN- Sujeito Indefinido", "Sintagma adverbial de negação" e "Outros sintagmas adverbiais" favorecem a implementação da próclise.

Nesse sentido, os resultados obtidos assemelham-se com os de Lobo (1992) para o contexto em que o verbo está precedido por um SN pronome pessoal. A pesquisadora encontra um total de 55 ocorrências para essa estrutura oracional e conclui: "Nesse contexto, a posição do clítico não se mostra variável, mas sim categoricamente pré-verbal" (LOBO, 1992, p.139). Os resultados alcançados nesta pesquisa não apontam para uma regra categórica, mas para um contexto variável, sendo esse favorecedor da anteposição, mostrando um peso relativo de .60. Vejamos alguns exemplos a seguir:

\section{(1):}

DOC: Há algo que marcou durante infância, algo que não consegues esqueceres que guardou no coração [ININT]?

INFO: "Que eu me lembro, eu [ININT] a minha pressa e agora ficou a dizer [ININT]. Uma história também com meus filho né? quando eles estão sentados eu converso com eles, eu gostava muito de dançar, gostava muito de ir a discoteca e ele me perguntava Antônica a discoteca é o quê? Donde tem música tipo assim uma festa a pessoa fica a vontade aí vai dançar vê o tempo passar [...]" (A.E, Faixa I, F, NP).

DOC: Está satisfeito com o sistema de transporte atualmente na nossa cidade?

INF: "Se quiser que eu Ihe diga com alguma frontalidade, Eu acredito que se passe nessa edição, mas ainda tem ... eu acho que devíamos... o Ministro dos Transportes já merece um cartão vermelho há muito tempo. É evidente que o sistema de transporte em Angola não funciona, nõ preenche nem um bocadinho as expectativas dos populares [...]" (C.A.R, Faixa I, M, NC).

Embora o programa computacional tenha selecionado a oração cujo verbo vem antecedido por "SN -Sujeito indefinido", como pode ser verificado no exemplo 03, como proporcionador da anteposição do pronome clítico (.69), o baixo número de dados encontrados no corpus impossibilita-nos a afirmar com segurança que esse contexto é fortemente favorecedor da próclise. 
(03)

DOC: Praticas algum esporte, senhor A.?

INF:“Epa... eu pratiquei muito tempo, mas há coisa de quine anos que já não faço isso, não faço isso, não sem fazer minhas caminhada, fazer minha ginástica de casa, que eu faço quase sempre de manhã, porque que eu, às vezes, não sei se é o hábito da tropa, mas por vezes, três da manhã não dá sono, só volto a dormir, às vezes, às cinco menos pouco às seis horas, então é obrigado, quer dizer, se num... se... se... se... se alguém não me tocare, então volto mesmo a dormir, mas, se ningúem, se alguém me tocare, eu já não durmo bem, então tem que fazer ginástica é na base disso, mas eu fiz Instituto Médico de Educação Física." (A. Faixa II, M, NC).

Bechara (2009) considera os advérbios como fator de próclise obrigatória. A literatura tem mostrado que esse contexto é favorecedor da variante proclítica (SCHEI, 2003; VIEIRA, 2012; LOBO, 1992; PETERSON, 2010). Contudo, de acordo com Torres de Morais (1995, p.125 apud SCHEl, 2003, p.179, grifo nosso) há advérbios que favorecem a ênclise:

De maneira semelhante ao que ocorre no caso dos quantificadores, existe um grupo de advérbios que sempre condiciona a próclise do pronome clítico. Entre esses, destacam-se os advérbios como já, bem, ainda sempre, os advérbios negativos como nunca, jamais, raramente e os operadores de foco como só, apenas, até, também, mesmo. Entretanto, ao contrário do que acontece com esse conjunto de "advérbios de próclise", os advérbios de tempo, assim como os advérbios sentenciais co-ocorrem com ênclise.

Assim, com a finalidade de averiguar a hipótese aventada por Torres de Morais (1995), separam-se os advérbios de negação e outros sintagmas adverbiais. Os resultados apontam que, quando antes do verbo vem um "sintagma adverbial de negação" (no corpus foi registrado de forma expressiva o não), a anteposiçã̃o do clítico é significativa (.96), sendo o uso quase categórico, enquanto que, outros sintagmas adverbiais apresentam um amplo quadro de variação, apresentando .52. Desse modo, coaduna-se com a ideia de Torres de Morais (1995). Os exemplos que seguem ilustram esses contextos: 
DOC: Quando volta a regressa?

INF: "Eu, quando vim pra aqui, pra Luanda, vim visitar a família e encontro então essa situação. Eu, com relação à lei, não poderia ter uma nova chance, então fui, organizei a documentação e pronto. Só que infelizmente, isso também não me levou muito tempo, né? Não me levou muito tempo, porque depois eu trabalhei como professore, o tempo em que me formei no ensino médio, mas depois levou mais seis meses e voltamo imediatamente pra tropa" (A.Faixall, $M, N C$ ).

(2)

DOC: Nessa fase não lembra-se de uma música ou uma história que os seus pais contavam ou os seus avós?

INF: "História já nãome recordo" (M.J.L, Faixa II, F, NP)

DOC: Do jeito que obedeciam antigamente?

A desobediência aqui dá-se, porque o país está a se desenvolver, os pais... com essa correria, acredito que não é só em Luanda, é... mesmo nos países mais desenvolvidos, Europa, Ásia, os pais hoje não tem tempo para os filhos e tentam cobrir esse tempo com o quê? Dando automóveis, iPads, é... tecnologias, não é? (J.P.T, Faixa I, F, NC).

(4)

DOC: Eu já sabia, porque a maior parte dos pescadores gosta de cozinhar. E qual é a sua especialidade na cozinha?

INF:“Bom, mas é... sendo aqui na praia, é mufete. Tá a ver o mufete, quando chama-se o peixe grelhado" (S.D, Faixa II, H, NP)

O programa mostrou como desfavorecedor contextos cuja lexia verbal vem precedida por "nenhum elemento (.16), "SN- sujeito nominal (.34), SN- demonstrativo (.16) e vocativo (.07). Contudo, chama atenção o número de ocorrências quando o verbo vem anteposto por "Nenhum elemento" e "SN-Sujeito". 


\subsubsection{As variáveis sociais}

O controle da variável extralinguística escolaridade tem-se mostrado altamente produtiva nas pesquisas variacionistas. Isso porque o processo de escolarização exerce influência sobre o comportamento linguístico do indivíduo, pois Ihe possibilita adquirir hábitos linguísticos que gozam de prestígio socialmente e evitar as formas que são objetos de julgamento negativo. Nesse sentido, de acordo com Pimpão (1999, p.90 apud FREITAG, 2011, p. 52), "O efeito da escolaridade a variáveis linguísticas prevê o uso mais próximo à norma gramatical para os níveis escolares mais elevados". Porém, fenômenos que são imunes à estigmatização social tendem a não indicar uma bipolarização de normas, como, por exemplo, o fenômeno em foco nesta pesquisa e estudado por Carneiro (2017, p.169) na língua brasileira, chegando às seguintes conclusões: "O confronto das amostras de fala feirense, culta e não culta, demonstrou que não há diferenças entre as vertentes. A próclise é a opção dos falantes em todos os contextos".

Os resultados da variável escolaridade podem ser observados na tabela a seguir:

Tabela 05: Atuação da variável escolaridade no favorecimento da próclise em lexias verbais simples no Português falado em Luanda centralizar tabela e o título dela? Ver normas da revista

\begin{tabular}{c|c|c|c}
\hline Escolaridade & Apl./Ocorrências & Percentual & Pesos Relativos \\
\hline Baixa/ Nula & $219 / 250$ & $88 \%$ & $\mathbf{. 6 9}$ \\
\hline Superior & $161 / 257$ & $63 \%$ & .31 \\
\hline
\end{tabular}

De acordo com Rocha Lima (2011, p. 543), "A posição normal dos pronomes átonos é depois do verbo (ênclise)". Sabe-se que a prescrição gramatical é adquirida no ambiente escolar, por isso a hipótese aventada inicialmente era que a ênclise fosse encontrada no desempenho linguístico dos indivíduos cultos. Como pode ser observado na tabela 2, os informantes com baixa ou nula escolaridade preferem a próclise, apresentando um peso relativo de (.69) enquanto os que possuem nível superior nota-se uma queda da posição préverbal, com peso relativo de (.31).

Os resultados aqui alcançados sugerem que a hipótese levantada de que a ênclise seria encontrada com uma maior frequência na fala dos sujeitos usuários da norma culta, coadunando assim com Pimpão (1999), pois os escolarizados apresentam em seu repertório 
linguístico "A posição normal dos pronomes átonos". Dessa forma, diferentemente das conclusões obtidas por Carneiro $(2017)^{3}$, a variável nível de escolaridade, na comunidade de fala angolana, aponta para uma bipolarização de normas no que concerne ao objeto estudado, entretanto, ressaltamos que essa hipótese carece de outros estudos que analisem outros contextos sintáticos e variáveis independentes do fenômeno em estudo no português luandense para uma melhor verificação da ideia aqui defendida.

A segunda variável extralinguística selecionada pelo programa foi o Local de Nascimento dos informantes. A seguir, apresentam-se os resultados alcançados nessa rodada:

Tabela 06: Atuação da variável local de nascimento no uso da colocação pronominal no português falado em Luanda

\begin{tabular}{c|c|c|c}
\hline $\begin{array}{c}\text { Local de Nasci- } \\
\text { mento }\end{array}$ & Apl./Ocorrências & Percentual & Pesos Relativos \\
\hline Luanda & $125 / 201$ & $62 \%$ & .35 \\
\hline Interior & $225 / 306$ & $83 \%$ & $\mathbf{. 5 9}$ \\
\hline
\end{tabular}

Como pode ser observado na tabela acima, o local de nascimento do falante mostrou-se um grupo de fator que favorece a colocação préverbal, sendo os informantes oriundos do interior os que mais usam a próclise (peso relativo .59) em comparação àqueles que nasceram na capital (peso relativo .35).

Esses dados precisam ser compreendidos não apenas quantitativamente, mas também à luz da sócio-história dessa comunidade de fala, pois como adverte Lucchesi (2015, p.57, grifo nosso):

Ao circunscrever a análise do encaixamento social dos processos de variação e mudança à descrição dos resultados quantitativos dos fatores sociais considerados isoladamente, o resultado da grande maioria das análises sociolinguísticas que se tem feito até então é o estabelecimento de relações mecanicistas e a-históricas entre a variável em foco e os fatores sociais.

Luanda é uma cidade marcada não apenas por um multilinguismo, coabitando cerca de 40 línguas africanas, como também por um

3. Vale ressaltar que este estudo não é de cunho quantitativo e sim descritivo. 
multidialetalismo. Essa realidade linguística começa a ser formada a partir da segunda metade do século XIX, pois muitos indivíduos sofrendo as consequências da guerra civil que durou 27 anos (19752002) migraram para Luanda com a esperança de uma vida melhor. Esses migrantes tiveram que aprender a língua portuguesa através da oralidade, sem terem a oportunidade de passarem pelo processo de escolarização.

Nesse sentido, mesmo que estatisticamente o Goldvarb X não tenha selecionado a variável "Língua Materna", mas com a finalidade de aclarar os resultados aqui sistematizados, procura-se estabelecer uma correlação entre essa variável e a discutida nessa seção. Os filhos dos migrantes que nasciam em Luanda, diferentemente dos seus pais, já tinham o português como língua nativa. Assim, os resultados percentuais alcançados mostram que os informantes que têm as línguas africanas como materna usam expressivamente a próclise, perfazendo um total de $83 \%$ (226 de um total 272 ocorrências), e, em relação aos luandenses que possuem o português como língua materna, foi encontrado uma porcentagem menor, cerca de $65 \%$ de um total de 235 ocorrências, dessas, 157 foram a colocação pré-verbal. Portanto, a relação entre ambas as variáveis extralinguísticas mostra que os indivíduos do interior e os que possuem o português como segunda língua preferem majoritariamente a próclise em detrimento da forma canônica ensinada na escola, a ênclise.

\section{CONSIDERAÇÕES FINAIS}

Defende-se a ideia de que, para uma melhor compreensão da formação sócio-histórica da heterogeneidade linguística do PB, necessita-se não apenas contrastar essa variedade a europeia, mas compará-la as outras ex-colônias portuguesas, a exemplo de Angola, pois esse cotejo pode trazer elementos que contribuam com as discussões sobre as consequências do contato linguístico do PB com as línguas africanas na constituição dessa variedade (PETTER, 2008).

Assim, inicialmente, procurou-se realizar uma revisão de literatura da colocação dos pronomes clíticos no Português do Brasil. Os estudos apontam que a anteposição do pronome é peculiar da realidade linguística da variedade brasileira (CARNEIRO, 2003; FERREIRA, ALKMIM, 2003). Nesse sentido, esses resultados serviram de base para destacar as confluências sociolinguísticas entre ambas as nações. 
Este trabalho teve o objetivo de investigar a colocação dos pronomes clíticos em estruturas com lexias verbais simples, ou seja, com um único verbo e os resultados alcançados apontam para uma aproximação entre o PB e o PA, confirmando a hipótese levantada, sendo a variante proclítica a preferida dos angolanos, perfazendo um total de $75 \%$ de 507 ocorrências. Nesse sentido, o programa Goldvarb $X$ selecionou como favorecedora da implementação da próclise as variáveis linguísticas "tipo de oração", "clítico" e "elemento que antecede o verbo". $\mathrm{E}$, em relação às variáveis extralinguísticas formam eleitas "escolaridade" e "local de nascimento".

Quando o verbo está em posição inicial absoluta, a norma padrão condena a anteposição do clítico. Porém, a literatura tem mostrado que esse contexto é fortemente favorecedor da próclise na língua portuguesa brasileira, o que não se observa nem na norma vernacular de Portugal em que a ênclise é categórica (VIEIRA, 2012). Esse contexto, na variedade luandense, assim como PB, favorece a próclise.

Portanto, essas semelhanças sintáticas podem ser compreendidas como uma forma dos angolanos estarem firmando a sua identidade linguística, pois como defende Teixeira (2008, 2013), o português falado nessa comunidade de fala está em processo de formação. $\mathrm{E}$, dessa forma, "[...] o caminho angolano parece, mais uma vez, desembocar em terras brasileiras como fizeram milhares de africanos séculos atrás" (SANTOS, 2007, p.168). Assim, este estudo contribuiu para a descrição da variedade angolana, apresentando as semelhanças existentes entre essas duas ex-colônias de Portugal.

\section{REFERÊNCIAS BIBLIOGRÁFICAS}

ARAÚJO, S. S. F. O português popular do seminário baiano: fundamentos teóricos, sócio-históricos e empíricos. In: LOPES, Norma da Silva; OLIVEIRA, Josane Moreira de; PARCERO, Lúcia Maria de Jesus (Org). Estudos sobre o português do Nordeste: língua, lugar e sociedade. São Paulo: Blucher, 2017.

ANDRADE, A. L. de; CARNEIRO, Zenaide de Oliveira Novais . A posição e a colocação de clíticos em predicados complexos: o português brasileiro visto a partir de duas vertentes. Filologia e Linguística Portuguesa (Online), v. 16, p. 125, 2014.

BECHARA, E. Moderna gramática da língua portuguesa. 37. ed. ver., ampl. e atual. Rio de Janeiro: Nova Fronteira, 2009.

BRITO, J. F. A. O objeto direto (ana)fórico no falar rural baiano. In: ALMEIDA, N. L. F. de; CARNEIRO, Z. O. N. (Org.). Variação Linguística no Semiárido Baiano. Feira de Santana: 
UEFS Editora, 2014.

CARNEIRO, Z. O. N. Colocação de clíticos em orações finitas em duas vertentes do português oral feirense: um contexto não variável. In: ALMEIDA, N. L. F. de; ARAUJO, S. S. de F.; TEIXEIRA, E. S. P.; CARNEIRO, Z. O. N.. (Org.). Variação Linguística em Feira de Santana. Feira de Santana: UEFS Editora, 2016, v. 1, p. 141-174.

CYRINO, S. M. L. Observações sobre a mudança diacrônica no português do Brasil: objeto nulo e clíticos. In: ROBERTS, Ian; KATO, Mary (Org.). Português brasileiro: uma viagem diacrônica. Campinas: Editora da Unicamp, 1993, p. 163-184.

FEREIRA, W. M. A C; ALKMIM, M. G. R. de. A colocação do pronome clítico na fala do dialeto mineiro. I CONGRESSO NACIONAL DE ESTUDOS LINGUíSTICOS. Vitória-ES, 18 A 21 de outubro de 2011,

FREITAG, R.M. K. O "social" da sociolinguística: o controle de fatores sociais. Diadorim (Rio de Janeiro), v. 8, p. 43-58, 2011.

GALVES, C.; LOBO, T. Ordem dos clíticos. In: LOBO, Tânia; OLIVEIRA, K., (Org). África à vista: dez estudos sobre o português escrito por africanos no Brasil do século XIX [online]. Salvador:EDUFBA, 2009. pp. 174-207. Disponível em: <http://books.scielo. org>. Acesso em: 06.mar.2017.

LABOV, W. Padrões sociolinguísticos. São Paulo: Parábola, 2008 [1972].

LUCCHESI, D. As duas grandes vertentes da história sociolinguística do Brasil (1500-2000). DELTA. São Paulo. v.17, n.1, p. 97-132, 2001. A diferenciação da língua portuguesa no Brasil e o contato entre línguas. Estudos de Linguistica Galega, v. 4, p. 45-65, 2012.

Língua e Sociedade partidas: a polarização sociolinguística do Brasil. São Paulo: Contexto, 2015.

LOBO, T. A colocação dos pronomes clíticos em português: duas sincronias em confronto. Dissertação de Mestrado. Faculdade de Letras da Universidade de Lisboa, Lisboa, 1992.

MATTOS E SILVA, R. V. Ensaios para uma sócio-história do português brasileiro. São Paulo: Parábola Editorial, 2004.

NUNES, J. M. Direção de clitização, objeto nulo e pronome tônico na posição de objeto em português brasileiro. In: ROBERTS, I.; KATO, M. (Org.). Português brasileiro: uma viagem diacrônica. Campinas: Editora da Unicamp, 1993, p. 207-222.

PETERSON, M. S. A ordem dos clíticos pronominais em lexias verbais simples e complexas em cartas de leitor: uma contribuição da sociolinguística variacionista. 
Dissertação (Mestrado) - UFRJ/ FL/ Programa de Pós-Graduação em Letras Vernáculas. Rio de Janeiro: UFRJ/FL, 2010.

PETTER, M. M.T. Uma hipótese explicativa do contato entre o português e as línguas africanas. Papia, v. 17, p. 9-19, 2007.

ROCHA LIMA, C. H. da. Gramática normativa da língua portuguesa. 49. ed. Rio de Janeiro: José Olympio, 2011.

SANKOFF, D.; TAGLIAMONTE, S. A.; SMITH, Eric.GoldvarbX: amultivariateanalysisapplication. Toronto: Departmento $f$ Linguistics; Ottawa: Departmentof Mathematics.2005. Disponível em: <http://individual.utoronto.ca/ tagliamonte/Goldvarb/GV_index.htm\#ref>Acesso em: 18 de maio de 2018.

SANTOS, D. C. de O. Asintaxe dos pronominais átonos em perspectiva: um exame variacionista do fenômeno de cliticização em gêneros textuais do português do Brasil do século xx. Língua e Literatura, n. 29, p. 87-103. 2007-09

SANTOS, M. R. P. dos. Um estudo sobre a regência do verbo ir. In: TEIXEIRA, E. P.; ARAUJO, S. S. de F. (Org). Diálogos entre Brasil e Angola: o português d' aquém e d’além-mar. Feira de Santana: UEFS Editora, 2017, p. 145-173.

$\mathrm{SCHEl}, \mathrm{A}$. A colocação pronominal do português brasileiro: a língua literária brasileira. 2. ed. São Paulo: Humanistas/ FFLCH/ USP, 2003.

TEIXEIRA, E. P. O pronome você no português de Luanda. In: LIMA-HERNANDES, M. C.; MARÇALO, M. J.; MICHELETTI, G., MARTIN, V. L. de R. (Org.). A língua portuguesa no mundo. São Paulo: FFLCH-USP. Editora, 2008.

- Aspetos da pronominalização do português vernacular de Luanda: uma comparação com o português do Brasil. In: LOPES, N. da S.; BULHÕES L. P. S.; CARVALHO, C. dos S. (Org). Sociolinguística: estudo da variação, da mudança e da sócio-história do português brasileiro. Feira de Santana: EDUEFS, 2013, p.145-167.

VIEIRA, S. R.. Colocação pronominal nas variedades europeia, brasileira e moçambicana do português: para a definição da natureza do clítico em Português. In: BRANDÃO, S.F.; MOTA, M.A.C da. (Org.). Análise contrastiva de variedades do Português. Rio de Janeiro: In-Fólio, v. 1, p. 37-60, 2003.

VIEIRA, M. de F. O português europeu e a colocação dos pronomes átonos. Diacrítica, Porto, v.26, n.1, p.299-330, 2012.

Recebido em: 20/10/2018

Aceite em: 20/11/2018 